\title{
Microwave-Absorbing Characteristics and XRD Characterization of Magnetic Separation Products of Reductive Products of Ilmenite Concentrate
}

\author{
Xinying Wang ${ }^{1}$, Wei $\mathrm{Li}^{1,2}$, Libo Zhang ${ }^{2, *}$ and Jinhui Peng ${ }^{2, *}$ \\ 1 Faculty of Science, Kunming University of Science and Technology, Kunming 650093, China; \\ wangxy6578@163.com (X.W.); lwg3@163.com (W.L.) \\ 2 Key Laboratory of Unconventional Metallurgy, Ministry of Education, Kunming University of \\ Science and Technology, Kunming 650093, China \\ * Correspondence: libozh_ok@yeah.net (L.Z.); jhpeng_ok@yeah.net (J.P.); \\ Tel.: +86-871-519-2076 (J.P.); Fax: +86-871-519-1046 (J.P.) \\ Academic Editor: William Skinner \\ Received: 9 July 2016; Accepted: 17 August 2016; Published: 27 September 2016
}

\begin{abstract}
The microwave absorbing characteristics of magnetic separation products (magnetic and non-magnetic) of reductive products of ilmenite concentrate were measured by the method of microwave cavity perturbation and the magnetic separation products were characterized by X-Ray Diffraction (XRD). It was demonstrated that metallic iron was a strong microwave absorbing material, while $\mathrm{TiO}_{2}$ was a weak microwave absorbing material. The decrease of a strong microwave absorbing material and an increase of weak microwave absorbing material resulted in the great decrease of microwave absorbing characteristics of magnetic products by using a current intensity from 2.5 to 3.0 A. $\mathrm{FeTi}_{2} \mathrm{O}_{5}$ was a strong microwave absorbing material, the increasing content would lead to the significant increase of the microwave absorbing characteristics of non-magnetic products by using a current intensity from 2.0 to $4.0 \mathrm{~A}$. The conclusions could help us to optimize the ilmenite concentrate processing by microwaves and microwave cavity design.
\end{abstract}

Keywords: microwave-absorbing characteristics; magnetic separation; ilmenite concentrate; XRD characterization

PACS: 61.66.Fn; 81.40. $\pm \mathrm{z}$

\section{Introduction}

Ilmenite concentrate can be used directly to make pigment or prepare titanium metal, but it usually has to be processed to an intermediate product low in iron to minimize problems of reagent consumption and waste disposal. Two methods are used industrially for this purpose: (a) the pyrometallurgical method, which includes partial reduction of ilmenite with anthracite in an electric furnace to get cast iron and a slag rich in titanium or fusion with sodium sulfide or hydroxide at $600-700^{\circ} \mathrm{C}$; and (b) hydrometallurgical methods, which include leaching of ilmenite with hydrochloric acid or sulfuric acid, both under atmospheric or pressure leaching conditions.

The ilmenite concentrate usually needs higher reduction temperatures or needs additives to improve its reactivity when it is directly reduced [1]. The carbothermic reduction of the ilmenite at temperatures below about $1200{ }^{\circ} \mathrm{C}$ produces metallic iron and reduced forms of titanium oxides [2]. The reactivity of ilmenite can be improved by using the pre-oxidization process to increase the rate of ilmenite reduction and the rate of leaching [3], which is now a widely adopted practice in the processing of ilmenite ore for the production of $\mathrm{TiO}_{2}$ pigment and metallic titanium. 
However, these process still have drawbacks of higher energy because extensive chemical alteration is needed to facilitate the removal of iron from the ilmenite. Furthermore, due to the higher contents of $\mathrm{CaO}$ and $\mathrm{MgO}$ and complex mineralogy of the Panzhihua ilmenite, it is very difficult to upgrade the ilmenite to titanium-rich slag, which limits the development and utilization of the ilmenite deposit in the Panzhihua region; therefore there is an urgent need to develop new processing technologies to utilize the ilmenite resource efficiently for the future development of the titanium industry.

Since the pioneering studies carried out in mid-1980s by Gedye et al. (1986) and Giguere et al. (1986) [4,5], the use of microwaves as an energy source in chemistry, material processing fields, etc. has blossomed. A number of potential applications of microwave heating in the fields of chemistry, metallurgical engineering, the mineral or materials processing, synthesis of carbon nanomaterials, solid state synthesis of inorganic materials, preparation of inorganic nanostructures in liquid phase, synthesis of metal-organic frameworks, drying and environmental engineering etc., have been intensively investigated, and many aspects of them have been thoroughly reviewed [6-16], reflecting the fast development of microwave technology. It has well been documented that advantages in utilizing microwave technologies for processing minerals and materials compared with conventional heating include penetrating radiation, controlled electric field distribution, and selective and volumetric heating.

For metallurgical engineering fields with microwaves, Peng and Hwang (2015) have recently reviewed the application of microwave energy in the metallurgy field, with emphasis on both fundamentals of microwave heating and recent experimental efforts on extractive metallurgy via pyrometallurgical or hydrometallurgical routes [10], concluding that the next stage of research required to advance applications of microwave energy in industry should be focused on a combination of reactor design, electromagnetic measurement and simulation, ensuring that the full benefits of microwave heating can be realized, highlighting the imperativeness of investigations on the microwave absorbing characteristics of materials and minerals [8-16]. So far, however, there has been little discussion about the microwave absorbing characteristics of materials and minerals, resulting in difficulties in investigating the interaction mechanism between microwaves and materials, which limits the application of microwave heating in the industry, especially in the chemical and metallurgical industry [16]. Therefore, there is an urgent need to investigate the microwave absorbing characteristics of materials and minerals in detail and collect their dielectric properties, in order to prompt applications of microwave heating in all different kinds of fields.

For the microwave processing of ilmenite or ilmenite concentrate, Kelly and Rowson (1995) investigated the microwave reduction of the oxidized ilimenite concentrate, showing that the oxidation and reduction of iron in ilmenite concentrate between the ferrous and ferric states has been found to enhance its chemical activity [17]. Kingman et al. (1999) investigated the effects of microwave radiation upon the mineralogy and magnetic processing of a massive Norwegian ilmenite ore, showing that short periods of exposure can cause fracture at grain boundaries which leads to the formation of intergranular fractures [18]. This fracture coupled with an increase in remanent magnetization of the ilmenite mineral has been demonstrated to give rise to an increase in both concentrate grade and valuable mineral recovery. Cutmore et al. (2000) investigated the dielectric properties of some minerals [19]. Tong et al. (2004) evaluated the economic advantages of industrial applications of carbothermic reduction of metal oxides by microwave heating, showing that application of microwave heating reduced operating costs by $15 \%-50 \%$ compared to that of conventional method [20]. Itoh et al. (2007) studied the microwave oxidation of rutile which was extracted process, titanium dioxide is extracted from a natural ilmenite ore by the oxidation and magnetic separation followed by leaching with diluted acid [21]. Fan et al. (2009) studied the microwave irradiation modification of ilmenite for enhancing surfactants adsorption and bubble attachment [22]. Guo et al. (2011) carried out the microwave assisted grinding of the Panzhihua ilmenite ore, demonstrating that intergranular fractures occurred between ores and gangues other than transgranular fractures after microwave treatment, which would 
liberate minerals from each other effectively [23]. Chen et al. (2012), Zhao et al. (2014) reported the optimization of combined microwave pretreatment and magnetic separation of the Panzhihua ilmenite, showing that microwave pretreatment could enhance the magnetic separation of ilmenite and improve the recovery ratio of magnetite and ilmenite [24,25]. Nuri et al. (2014) reported that the microwave irradiation pretreatment could improve the ilmenite hydrophobicity and floatability in a wide $\mathrm{pH}$ range, improving the selective flotation of ilmenite from gangue minerals [26]. Mehdilo and Irannajad (2016) investigated the comparison of microwave irradiation and oxidation roasting as pretreatment methods for modification of physicochemical properties of ilmenite, concluding that using microwave irradiation as a pretreatment process, the improvement in the recovery of $\mathrm{TiO}_{2}$, and separation efficiency are much more efficient than those of oxidation roasting, reducing the consumption of activation and depressant agents [27]. However, according to the literature survey, there is still little information on the microwave absorbing characteristics of ilmenite or ilmenite concentrate. Recently, the authors' group has investigated the microwave absorbing characteristics of ilmenite concentrate containing different proportions of carbonaceous reduction agents [28], and the carbothermic reduction kinetics of ilmenite concentrate using sodium silicate, sodium chloride, and sodium borate as catalysts, respectively, and microwave-absorbing characteristics of reduction products [29-31], microwave absorbing characteristics of carbothermic reduced products of ilmenite and oxidized ilmenite [32], and the effect of temperature on dielectric property and microwave heating behavior of low grade Panzhihua ilmenite ore [33], obtaining some significant conclusions, which has allowed us to optimize the ilmenite concentrate processing by microwaves and the microwave cavity design.

The conventional methods used in the processing of ilmenite ores are gravity separation, high intensity magnetic separation (HIMS), Electrostatic separation or a conjunction of them. In order to fully utilize microwave technology in the ilmenite concentrate processing, the objective of the present study was focused on investigating the microwave-absorbing characteristics by the method of microwave cavity perturbation and X-Ray Diffraction (XRD) characterization of magnetic separation products of reductive products of ilmenite concentrate.

\section{Materials and Methods}

The ilmenite concentrate was obtained from Panzhihua Iron and Steel Company (Panzhihua, China).

Figure 1 illustrated the XRD of the ilmenite concentrate, revealing that concentrate consisted mostly of $\mathrm{FeTiO}_{3}$. The main chemical composition of the ilmenite concentrate was listed in Table 1.

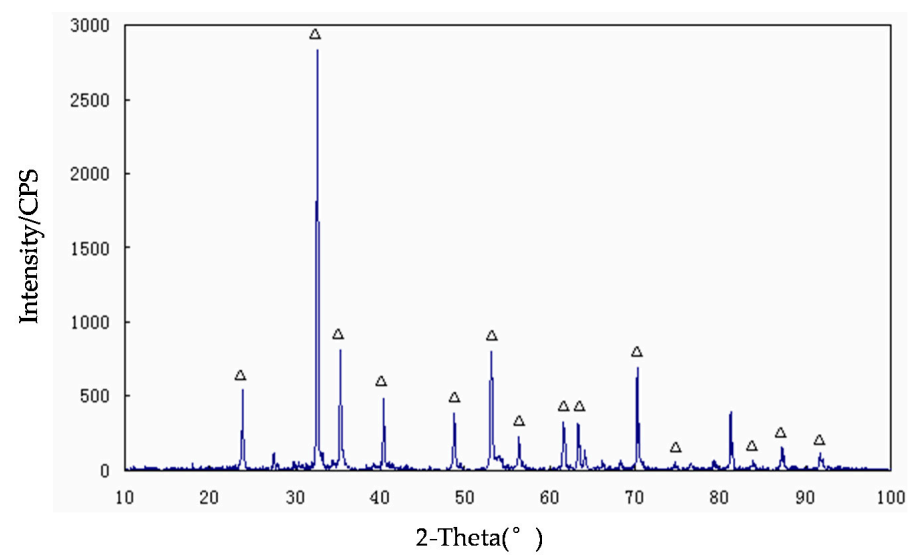

Figure 1. XRD spectra of ilmenite concentrate $\left(\mathrm{FeTiO}_{3} \triangle\right)$.

Table 1. Chemical composition of ilmenite concentrate (\%).

\begin{tabular}{cccccccc}
\hline Chemical Composition & $\mathbf{T F e}$ & $\mathrm{TiO}_{2}$ & $\mathbf{C a O}$ & $\mathbf{M g O}$ & $\mathrm{SiO}_{2}$ & $\mathbf{A}_{12} \mathbf{O}_{3}$ & $\mathbf{S}$ \\
\hline Content (wt \%) & 32.18 & 47.85 & 1.56 & 6.56 & 5.6 & 3.16 & $\leq 0.1$ \\
\hline
\end{tabular}


Magnetic separation trials were carried out to determine the liberation. Before the magnetic separation, the samples were ground for $60 \mathrm{~s}$ by using a crusher $(\mathrm{XMQ} 240 \times 90$, conical ball mill, Shandong Xinhai Mining Technology \& Equipment Inc., Yantai, China). Magnetic separations were realized on the electromagnetic separator (XCGS-73, magnetic tube, Jiangxi Walker Machinery Co., Ltd., Ganzhou, China) with a magnetic field intensity of $3.0 \mathrm{KOe}$, which is specified for the wet mode of separation. Process conditions: grinding time of 20-40 min; magnetic current of 2.5-4.5 A.

\subsection{Experimental Setup and Conditions}

The microwave heating set up ( $3 \mathrm{~kW}$, frequency $2.45 \mathrm{GHz}$ ) was illustrated in Figure 2 which was researched and developed by the authors' group [32]. A microwave system typically consists of a generator (magnetron) to produce the microwaves, a waveguide to transport the microwaves, an applicator (usually a cavity) to manipulate microwaves for a specific purpose, and a control system (tuning, temperature, power, etc.). In the present study, the power supply of the microwave heating set-up was two magnetrons at $2.45 \mathrm{GHz}$ frequency and $1.5 \mathrm{~kW}$ power, which was cooled by water circulation. The inner dimensions of the multi-mode microwave resonance cavity were $260 \mathrm{~mm}$ in height, $420 \mathrm{~mm}$ in lengthen and $260 \mathrm{~mm}$ in width. The temperature was measured using a type $\mathrm{K}$ thermocouple, placed in the closest proximity to the sample. The thermocouple provides feedback information to the control panel that controls the power to the magnetron, controlling the temperature of the sample during the microwave irradiation.

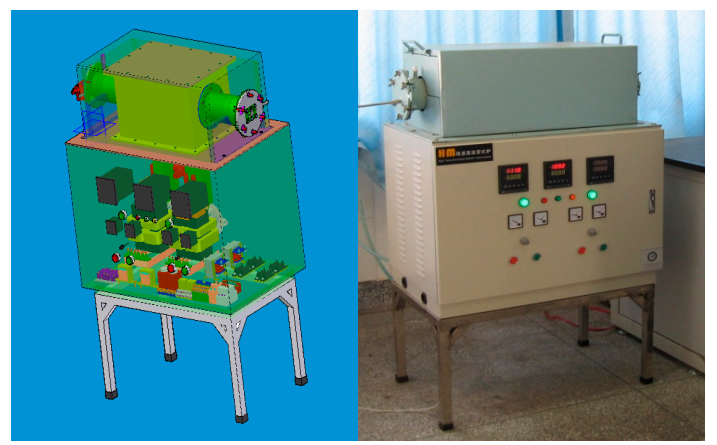

Figure 2. Schematic diagram (left) and photo (right) of the microwave heating apparatus.

The reduction of ilmenite concentrates by microwave heating was carried out as follows: the particle size was 180-200 mesh; the reduction temperature was $850-1200{ }^{\circ} \mathrm{C}$; the reduction time was $1.5 \mathrm{~h}$; the additive of sodium silicate was 5\%; the reduction agent was coke. Table 2 listed the proximate analysis of coke [32].

Table 2. The proximate analysis of coke.

\begin{tabular}{cccccc}
\hline Water Content & Ash & Volatile & Fixed Carbon & Total Sulfur (Dry Basis) & $\begin{array}{c}\text { Calorific Value } \\
\text { (Air Dry Basis) }\end{array}$ \\
\hline $1.93 \%$ & $27.80 \%$ & $1.41 \%$ & $70.80 \%$ & $2.68 \%$ & $23.64 \mathrm{MJ} / \mathrm{Kg}$ \\
\hline
\end{tabular}

\subsection{Measuring Principles of Microwave Absorbing Characteristics}

The principle and equipment for measuring the microwave absorbing characteristics of the resulting products using the microwave cavity perturbation method can be found in our previously published papers and patent $[28,34,35]$.

The equipment in the present study consists of a resonant sensor [34], sweeping signal, detector and (digital signal processors) DSP, interface circuit and computer. It was controlled by a software programmed in Visual Basic 6.0. 
The cavity perturbation technique was widely adopted for microwave dielectric properties measurements, which is based on the fact that cavities are high quality resonance structures [36]. Coupling between microwaves and materials is determined by electrical permittivity and magnetic permeability. The presence of a small piece of dielectric sample in the resonant cavity will cause a shift of resonant frequency and a decrease of the quality factor of the cavity. The decrease in the quality factor of the cavity is because of the presence of sample's dielectric loss. The dielectric constant and loss tangent of the specimen can then be calculated from the changes of resonance frequency and quality factor. In a word, the success of cavity perturbation method to calculate the microwave dielectric properties relies on measuring the values of the resonant frequency and quality factor accurately, before and after the insertion of the sample into the cavity. The cavity is calibrated with dimensionally identical sample of known permittivity.

Each material has intrinsic properties relative to the absorption of microwave energy. The most important property is the imaginary permittivity because it is proportional to the absorbed microwave power. The most important property is the dielectric constant, or complex relative permittivity. The permittivity is a measure of a material's ability to absorb and to store electrical potential energy. The measurement principle is that the microwave is coupled with the microwave cavity resonators; that is to say, is the measurement of the resonant frequency and the output voltage of the resonant sensor unloaded and loaded with samples. In this cavity, microwaves interact with the measured sample. When the sample is very small (the volume of the sample is much smaller than the volume of the cavity), the technique of perturbation can be applied $[28,34,36]$.

$$
\begin{gathered}
\frac{\Delta \omega}{\omega}=-\omega_{0}\left(\varepsilon_{r}^{\prime}-1\right) \int_{V e} E_{0}^{*} \cdot E d V / 4 W \\
\frac{1}{Q}-\frac{1}{Q_{0}}=2 \varepsilon_{0} \varepsilon_{r}^{\prime \prime} \int_{V e} E_{0}^{*} \cdot E d V / 4 W \\
W=\int_{V}\left[\left(E_{0}^{*} \cdot D_{0}+H_{0}^{*} \cdot B_{0}\right)+\left(E_{o}^{*} \cdot D_{1}+H_{0}^{*} \cdot B_{1}\right)\right] d V
\end{gathered}
$$

A vector network analyzer (HP9000/300, Agilent Technologies Inc., Santa Clara, CA, USA) is used to detect the frequency shift, and resultant quality factor. The whole measurement and network analyzer analysis were all controlled by a computer. In order to further minimize the error, the cavity was first calibrated with alumina and silica with their size and shape similar to the sample.

By using Equations (1)-(3), microwave absorbing characteristics of materials can be obtained through inversion by measuring variations of microwave output and resonant frequency of the resonant sensor unloaded and loaded with samples.

\subsection{XRD Characterization}

XRD data were obtained using X-ray powder diffractometer (D/max-2000, Rigaku, Tokyo, Japan) in the diffraction angle range $2 \theta=20^{\circ}-60^{\circ}$ equipped with Ni-filtered $\mathrm{Cu} \mathrm{K} \alpha$ radiation $(\lambda=1.5418 \AA)$ at a scanning rate of $0.25\left(^{\circ}\right) / \mathrm{min}$. The voltage and anode current operated were $40 \mathrm{kV}$ and $20 \mathrm{~mA}$, respectively. The software for the XRD analysis was MDI Jade 5.0.

\section{Results and Discussion}

The magnetic separation technique is based on the differences of magnetic susceptibilities of particles and can be carried out at various intensities and in different basic machine configurations. Magnetic and non-magnetic products can be obtained via magnetic separation of reduction products of ilmenite concentrates by using magnetic separator. Magnetic products can enrich iron substances, being that enriching irons maybe contain a small amount of iron oxide and a small amount of titanium dioxide inclusions. Non-magnetic products can enrich $\mathrm{TiO}_{2}$, perhaps by containing silicates and titanium dioxide with iron oxide inclusions [19]. 


\subsection{The Microwave-Absorbing Characteristics and XRD Characterization of Magnetic Products}

Figure 3 shows the microwave spectra of magnetic products, and Table 3 lists the parameters of microwave absorbing characteristics. Figure 4 illustrates the relationships between the current intensity and attenuation/microwave frequency, and bandwidth/quality factor. Through the evaluations of attenuation, microwave frequency, bandwidth and quality factor of microwave absorbing characteristics in Figure 3 and Table 2, it is found that the microwave absorbing characteristics of magnetic products changes in the order of $2.5 \mathrm{C}-3.0 \mathrm{C}-3.5 \mathrm{C}-4.0 \mathrm{C} \approx 4.5 \mathrm{C}$. The microwave absorbing characteristics of magnetic products is getting weaker using current intensities both from 2.5 to 3.0 A and from 3.5 to 4.0 A. In order to have a better understanding of the reason for the great changes of microwave absorbing characteristics, the XRD analysis of the reductive products of ilmenite concentrate, and magnetic products using current intensities of 3.5 and 4.0 A were carried out, as illustrated in Figure 4.

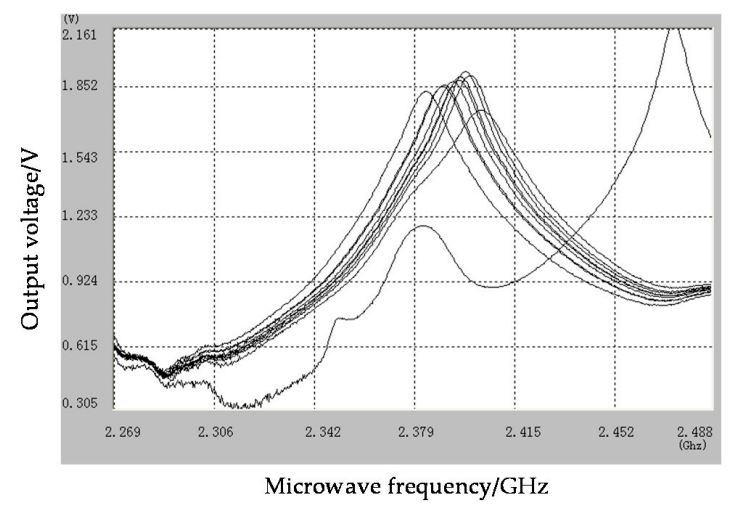

Figure 3. Microwave spectra of microwave absorbing characteristics for magnetic products.

Table 3. Measured parameters of microwave absorbing characteristics for the magnetic products.

\begin{tabular}{cccccc}
\hline NO & $\begin{array}{c}\text { Intensity } \\
\text { (A) }\end{array}$ & $\begin{array}{c}\text { Attenuation } \\
\text { Voltage (V) }\end{array}$ & $\begin{array}{c}\text { Frequency } \\
\text { (Ghz) }\end{array}$ & $\begin{array}{c}\text { Bandwidth } \\
\text { (Ghz) }\end{array}$ & $\begin{array}{c}\text { Quality } \\
\text { Factors (Q) }\end{array}$ \\
\hline Empty cavity & 0.0 & 2.2030 & 2.4744 & 0.0325 & 76.14 \\
Raw material & 0.0 & 1.7659 & 2.4037 & 0.0602 & 39.93 \\
1.5C & 1.5 & 1.8577 & 2.3836 & 0.0455 & 52.39 \\
2.0C & 2.0 & 1.9130 & 2.3955 & 0.0458 & 52.30 \\
2.5C & 2.5 & 1.8819 & 2.3897 & 0.0456 & 52.40 \\
3.0C & 3.0 & 1.9543 & 2.3979 & 0.0442 & 54.25 \\
3.5C & 3.5 & 1.9033 & 2.3935 & 0.0457 & 52.37 \\
4.0C & 4.0 & 1.9355 & 2.3999 & 0.0462 & 51.94 \\
4.5C & 4.5 & 1.9283 & 2.3960 & 0.0454 & 52.77 \\
4.8C & 4.8 & 1.8895 & 2.3904 & 0.0454 & 52.65 \\
\hline
\end{tabular}

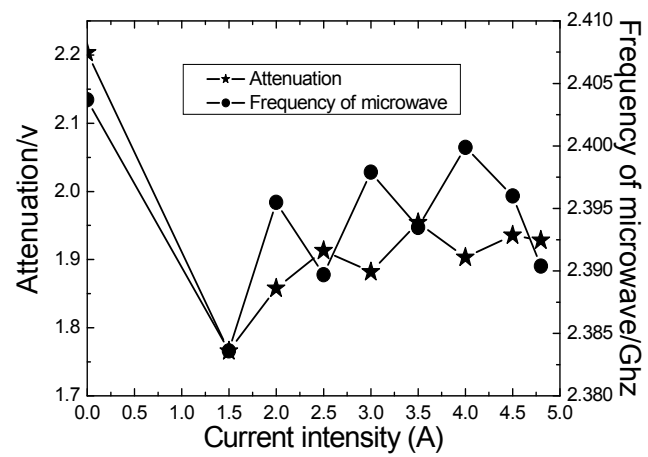

(a)

Figure 4. Cont. 


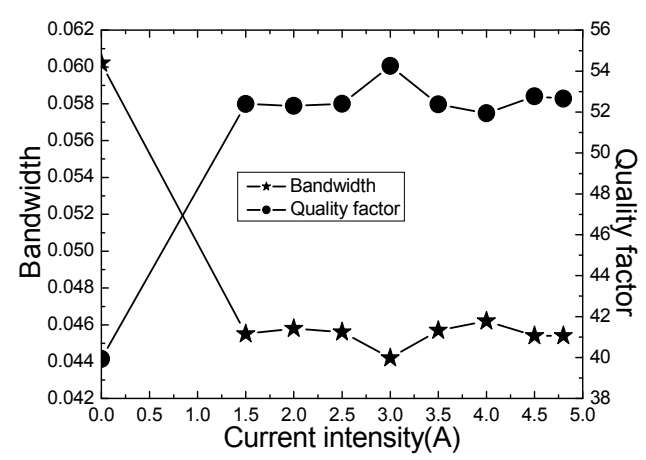

(b)

Figure 4. Relationship between current intensity and (a) attenuation and microwave frequency; and (b) bandwidth and quality factor.

Figure $5 \mathrm{a}$ shows that the reductive products under the conditions of a reductive temperature of $1150{ }^{\circ} \mathrm{C}$ and a reductive time of $1.5 \mathrm{~h}$ have phases of metallic iron $(\alpha-\mathrm{Fe}), \mathrm{FeTi}_{2} \mathrm{O}_{5}$ (isomorphic phase of $\mathrm{MgTi}_{2} \mathrm{O}_{5}$, having similar characteristics peak), rutile $\mathrm{TiO}_{2}$, and a small amount of $\mathrm{Ti}_{7} \mathrm{O}_{13}$ $\left(\mathrm{TiO} \cdot 6 \mathrm{TiO}_{2}\right)$, not having the phase of low valence titanium oxides, suggesting that the reductive temperature and reductive time are reasonable. The powder metallic iron is a strong microwave absorbing characteristics material, resulting in the local higher temperature, prompting the formation of $\mathrm{Ti}_{7} \mathrm{O}_{13}$.

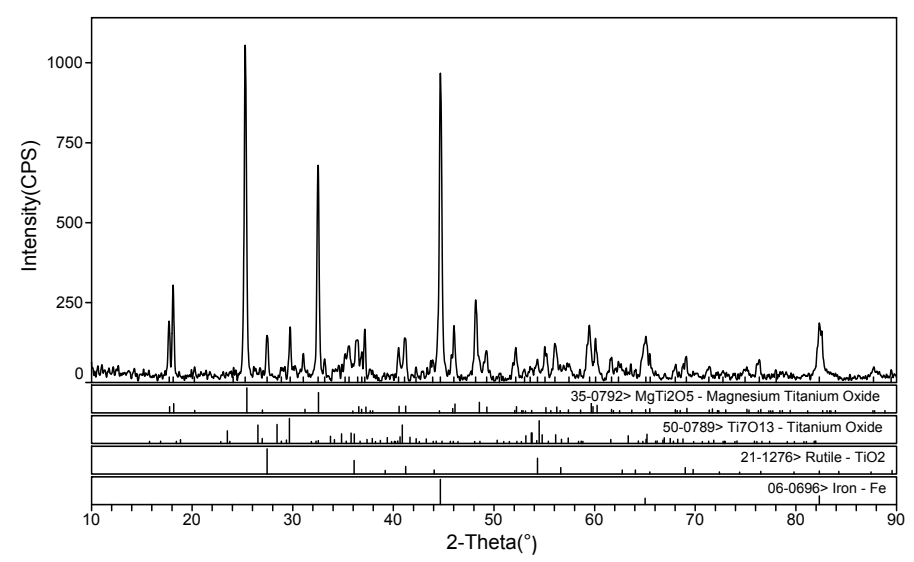

(a)

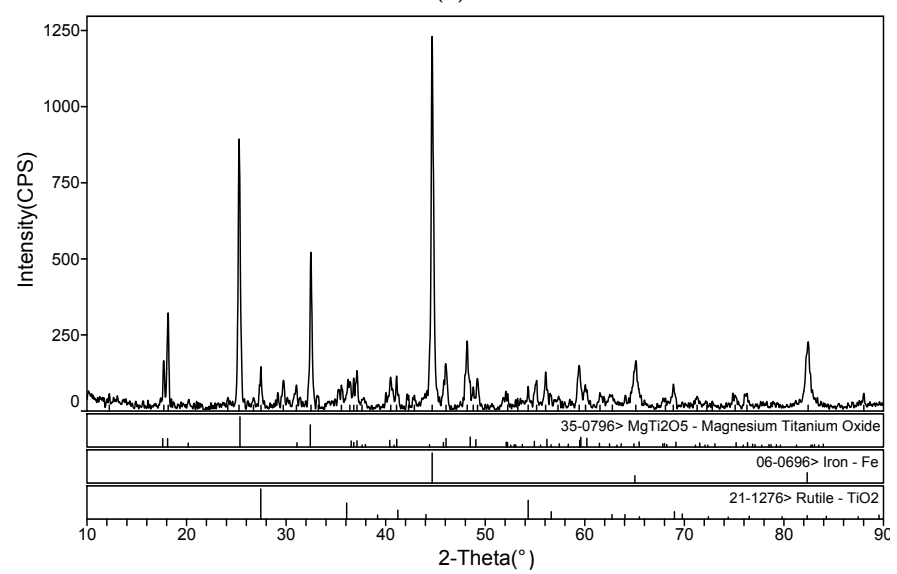

(b)

Figure 5. Cont. 


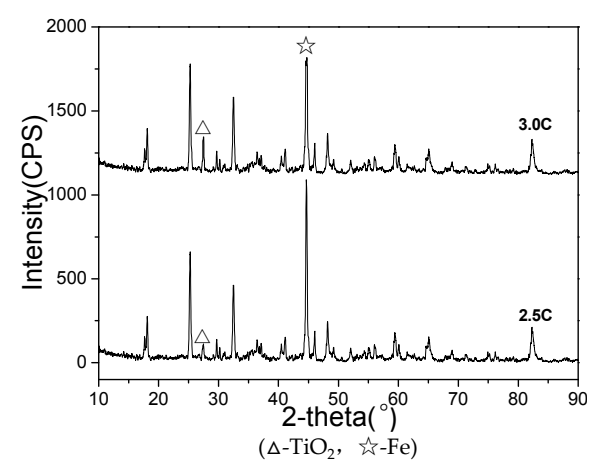

(c)

Figure 5. XRD patterns of magnetic products (a): reduction temperature $1150{ }^{\circ} \mathrm{C}$, reduction time $1.5 \mathrm{~h}$; (b): the sample number is $2.5 \mathrm{C}$; and (c): samples $2.5 \mathrm{C}$ and $3.0 \mathrm{C}$.

Figure $5 b$ is similar to the Figure $5 a$, showing that the reductive products also have phases of metallic iron $(\alpha-\mathrm{Fe}), \mathrm{FeTi}_{2} \mathrm{O}_{5}$ (isomorphic phase of $\mathrm{MgTi}_{2} \mathrm{O}_{5}$, having similar characteristics peak), and a small amount of rutile $\mathrm{TiO}_{2}$. The intensity of the iron crystal face 100 at the diffraction angle of $44.68^{\circ}$ in Figure $4 \mathrm{~b}$ is stronger than that in Figure $4 \mathrm{a}$, and the intensity of $\mathrm{FeTi}_{2} \mathrm{O}_{5}$ at the diffraction angle of $25.28^{\circ}$ and the intensity of $\mathrm{TiO}_{2}$ at the diffraction angle of $27.48^{\circ}$ become small, suggesting that the iron after magnetic separation was enriched in the magnetic products, and a small amount of $\mathrm{TiO}_{2}$ was due to the inclusions of magnetic products.

Figure $5 \mathrm{c}$ shows that the samples $2.5 \mathrm{C}$ and $3.0 \mathrm{C}$ have the same patterns, having phases of metallic iron and a small amount of $\mathrm{TiO}_{2}$. The intensity of iron crystal face 100 at the diffraction angle of $44.68^{\circ}$ for sample of $2.5 \mathrm{C}$ is stronger than that of sample of $3.0 \mathrm{C}$; the intensity of $\mathrm{TiO}_{2}$ at the diffraction angle of $27.48^{\circ}$ for the sample of $3.0 \mathrm{C}$ is stronger than that of the sample of $2.5 \mathrm{C}$, demonstrating that the magnetic iron was enriched in the magnetic products during the magnetic separation process of the reduction products, leading to the decrease of iron content. The total mechanical force upon the particles is greater than that of magnetic force during the magnetic separation process, resulting in the decrease of powder metallic iron, while the increase of inclusions of rutile $\mathrm{TiO}_{2}$. The powder metallic iron is a strong microwave absorbing characteristics material, while the $\mathrm{TiO}_{2}$ is a weak microwave absorbing characteristics material; therefore, the decrease of iron and increase of $\mathrm{TiO}_{2}$ leads to the weak microwave absorbing characteristics material of mixtures, which makes a significant change of microwave absorbing characteristics from a sample using a current intensity of 2.5 A to a sample using a current intensity $3.0 \mathrm{~A}$.

\subsection{The Microwave-Absorbing Characteristics and XRD Characterization of Non-Magnetic Products}

Figure 6 shows the microwave spectra of non-magnetic products, and Table 4 lists the parameters of microwave absorbing characteristics. Figure 7 illustrates the relationship between the current intensity and attenuation/microwave frequency, and bandwidth/quality factor.

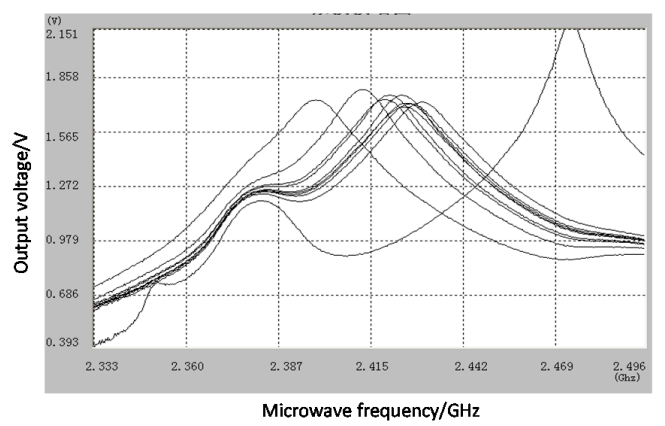

Figure 6. Microwave spectra of microwave absorbing characteristics for non-magnetic products. 
Table 4. Measured parameters of microwave-absorbing characteristics for the non-magnetic products.

\begin{tabular}{cccccc}
\hline NO & $\begin{array}{c}\text { Intensity } \\
(\mathbf{A})\end{array}$ & $\begin{array}{c}\text { Attenuation } \\
\text { Voltage (V) }\end{array}$ & $\begin{array}{c}\text { Frequency } \\
\mathbf{( G h z )}\end{array}$ & $\begin{array}{c}\text { Bandwidth } \\
\text { (Ghz) }\end{array}$ & $\begin{array}{c}\text { Quality } \\
\text { Factors (Q) }\end{array}$ \\
\hline Empty cavity & 0.0 & 2.2029 & 2.4745 & 0.0325 & 76.14 \\
Raw material & 0.0 & 1.8204 & 2.4127 & 0.0614 & 39.29 \\
1.5F & 1.5 & 1.7885 & 2.4245 & 0.0714 & 33.95 \\
$2.0 \mathrm{~F}$ & 2.0 & 1.7657 & 2.4194 & 0.0708 & 34.17 \\
$2.5 \mathrm{~F}$ & 2.5 & 1.7888 & 2.4208 & 0.0690 & 35.08 \\
3.0F & 3.0 & 1.7628 & 2.3990 & 0.0574 & 41.79 \\
$3.5 \mathrm{~F}$ & 3.5 & 1.7400 & 2.4274 & 0.0790 & 30.72 \\
$4.0 \mathrm{~F}$ & 4.0 & 1.7234 & 2.4250 & 0.0797 & 30.42 \\
$4.5 \mathrm{~F}$ & 4.5 & 1.7463 & 2.4257 & 0.0781 & 31.06 \\
$4.8 \mathrm{~F}$ & 4.8 & 1.7495 & 2.4305 & 0.0605 & 40.17 \\
\hline
\end{tabular}

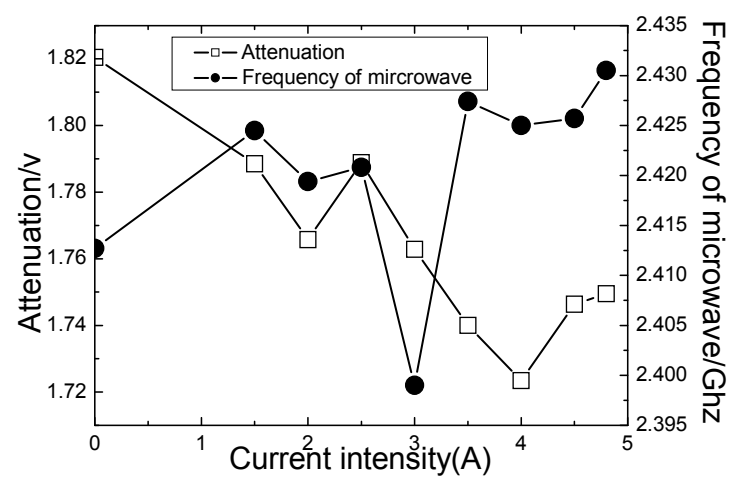

(a)

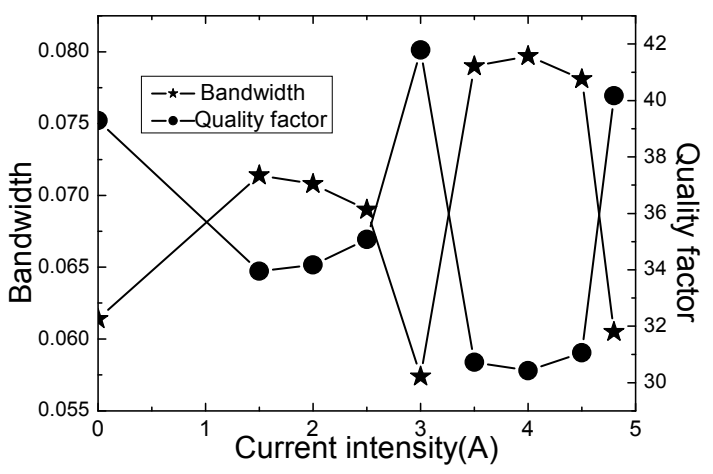

(b)

Figure 7. Relationship between current intensity and (a) attenuation and microwave frequency; and (b) bandwidth and quality factor.

Through the evaluations of attenuation, microwave frequency, bandwidth and quality factor of microwave absorbing characteristics in Figure 7 and Table 4, it is found that the microwave absorbing characteristics of non-magnetic products become stronger under the conditions of current intensity of both 2.5 and $4.0 \mathrm{~A}$, but the microwave absorbing characteristics of non-magnetic products by using a current intensity of $4.0 \mathrm{~A}$ is stronger than at $2.5 \mathrm{~A}$. In order to explain the reason for the significant change of microwave absorbing characteristics of non-magnetic products, the XRD patterns of the non-magnetic products by using current intensities of 2.5 and $4.0 \mathrm{~A}$ was compared, as illustrated in Figure 8.

Figure 8a shows that non-magnetic products by using current intensity of $2.5 \mathrm{~A}$ has phases of $\mathrm{FeTi}_{2} \mathrm{O}_{5}$ (isomorphic phase of $\mathrm{MgTi}_{2} \mathrm{O}_{5}$, having similar characteristics peak), rutile $\mathrm{TiO}_{2}$, and small 
amounts of $\alpha-\mathrm{Fe}$ and $\mathrm{Ti}_{7} \mathrm{O}_{13}$, not having phase of low valence titanium oxides. The iron phase is due to the inclusions of $\mathrm{TiO}_{2}$, and brought into the non-magnetic products, demonstrating that there are inclusions between iron and titanium in the reductive products.

Figure $8 \mathrm{~b}$ shows that that non-magnetic products by using current intensity of $4.0 \mathrm{~A}$ has phases of $\mathrm{FeTi}_{2} \mathrm{O}_{5}$ (isomorphic phase of $\mathrm{MgTi}_{2} \mathrm{O}_{5}$, having similar characteristics peak), rutile $\mathrm{TiO}_{2}$, and small amounts of $\alpha$-Fe and $\mathrm{Ti}_{7} \mathrm{O}_{13}$, not having phase of low-valence titanium oxides. The iron phase is due to the inclusions of $\mathrm{TiO}_{2}$, and brought into the non-magnetic products. The intensity of diffraction peak of the iron phase in the non-magnetic products decreases gradually with the increase of the current intensity from 2.5 to $4.0 \mathrm{~A}$. Thus, the microwave absorbing characteristics of non-magnetic products should decrease gradually with the increase of the current intensity from 2.5 to 4.0 A. However, it is shown that the microwave absorbing characteristics of non-magnetic products actually increases, the reason maybe that there is a strong microwave absorbing material produced in the products, compromising the decreasing trend. It can be found in Figure 8 that the intensity of diffraction peak phases of $\mathrm{FeTi}_{2} \mathrm{O}_{5}$ by using a current intensity of $2.5 \mathrm{~A}$ is 1635 counts per second (CPS), while, the intensity of diffraction peak phases of $\mathrm{FeTi}_{2} \mathrm{O}_{5}$ by using a current intensity of $4.0 \mathrm{~A}$ is $1796 \mathrm{CPS}$, indicating that $\mathrm{FeTi}_{2} \mathrm{O}_{5}$ is a strong microwave absorbing material, the increasing content will lead to the significant increase of the microwave absorbing characteristics of non-magnetic products by using current intensities from 2.5 to $4.0 \mathrm{~A}$.

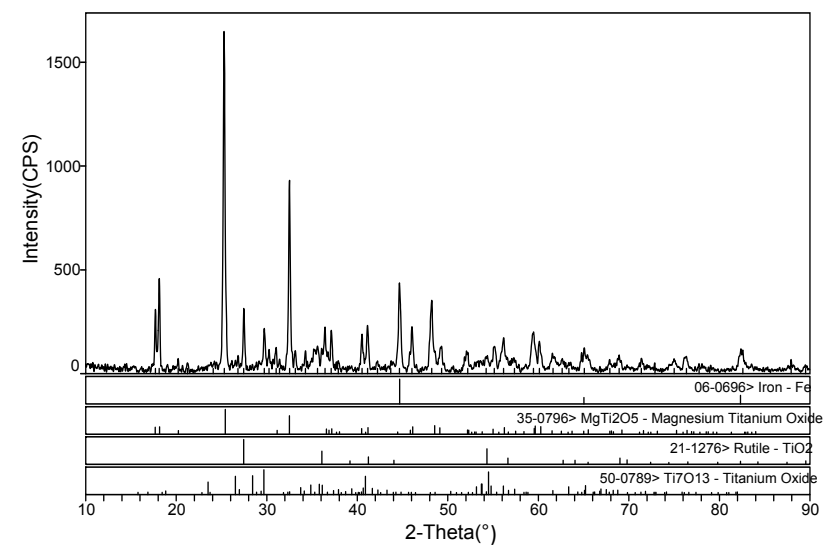

(a)

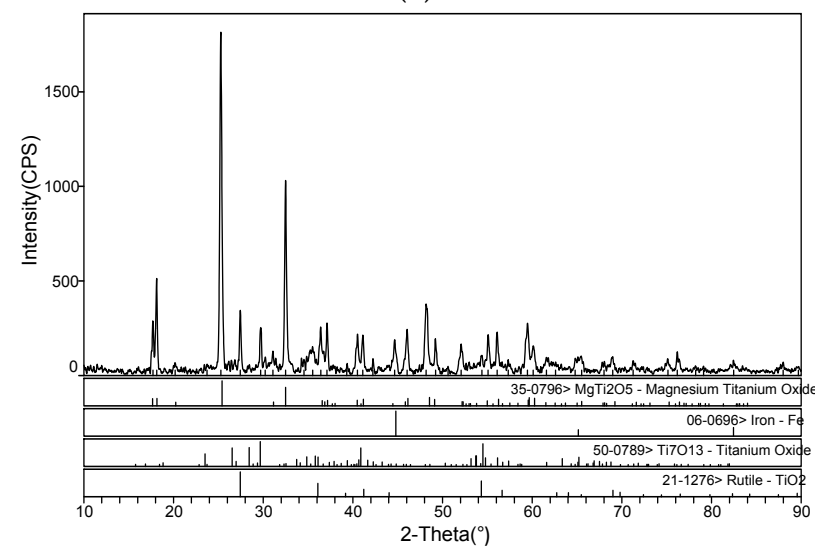

(b)

Figure 8. XRD pattern of non-magnetic product (a) the sample number is $2.5 \mathrm{~F}$; and (b) the sample number is $4.0 \mathrm{~F}$.

\section{Conclusions}

In summary, the microwave-absorbing characteristics and XRD characterization of magnetic separation products (magnetic and non-magnetic) of reduction products of ilmenite concentrate were 
investigated. The results suggest that the metallic iron is a strong microwave absorbing material, and $\mathrm{TiO}_{2}$ is a weak microwave absorbing material. The decrease of strong microwave absorbing material and increase of weak microwave absorbing material results in the significant decrease of microwave absorbing characteristics of magnetic products by a using intensity from 2.5 to 3.0 A. $\mathrm{FeTi}_{2} \mathrm{O}_{5}$ is a strong microwave absorbing material, and the increasing content will lead to the greater increase of the microwave absorbing characteristics of non-magnetic products by using a current intensity from 2.0 to 4.0 A. The findings of the study have important implications for optimizing ilmenite concentrate processing by microwaves and microwave cavity design and the optimization process is being carried out underway.

Acknowledgments: The authors would like to express their gratitude for the financial supports of the Joint Fund of National Natural Science Foundation of China and Yunnan (Grant No. U1502273), National Natural Science Foundation of China (Grant No. 21061007), National Key Basic Research Program (973 Program, Grant No. 2014CB643406), the State Key Laboratory of Complex Nonferrous Metal Resources Clean Utilization, Kunming 650093 (Grant No. CNMRCUKF1606), and Reserve Talents of Middle-aged and Young Academic Technology Leaders in Yunnan Province (Grant No. 2011CI010).

Author Contributions: Xinying Wang and Wei Li performed the laboratory experiments and were responsible for the XRD analyses; all authors analyzed the data; Jinhui Peng and Libo Zhang contributed to the conception of the study and were involved in the manuscript preparation. All authors read and approved the manuscript. All authors read and approved the manuscript.

Conflicts of Interest: The authors declare no conflict of interest.

\section{References}

1. Kucukkaragoz, C.S.; Eric, R.H. Solid state reduction of a natural ilmenite. Miner. Eng. 2006, 19, $334-337$.

2. El-Tawil, S.Z.; Morsi, I.M.; Yehia, A.; Francis, A.A. Alkali reductive roasting of ilmenite ore. Can. Metall. Q. 1996, 35, 31-37. [CrossRef]

3. Sarker, M.K.; Rashid, A.K.M.B.; Kurny, A.S.W. Kinetics of leaching of oxidized and reduced ilmenite in dilute hydrochloric acid solutions. Int. J. Miner. Process. 2006, 80, 223-228. [CrossRef]

4. Gedye, R.; Smith, F.; Westaway, K.; Ali, H.; Baldisera, L.; Laberge, L.; Rousell, J. The use of microwave ovens for rapid organic synthesis. Tetrahedron Lett. 1986, 27, 279-282. [CrossRef]

5. Giguere, R.J.; Bray, T.L.; Duncan, S.M.; Majetich, G. Application of commercial microwave ovens to organic synthesis. Tetrahedron Lett. 1986, 27, 4945-4948. [CrossRef]

6. Baghbanzadeh, M.; Carbone, L.; Cozzoli, P.D.; Kappe, C.O. Microwave-assisted synthesis of colloidal inorganic nanocrystals. Angew. Chem. Int. Ed. 2011, 50, 11312-11359. [CrossRef] [PubMed]

7. Gawande, M.B.; Shelke, S.N.; Zboril, R.; Varma, R.S. Microwave-assisted chemistry: Synthetic applications for rapid assembly of nanomaterials and organics. Acc. Chem. Res. 2014, 47, 1338-1348. [CrossRef] [PubMed]

8. Kitchen, H.J.; Vallance, S.R.; Kennedy, J.L.; Tapia-Ruiz, N.; Carassiti, L.; Harrison, A.; Whittaker, A.G.; Drysdale, T.D.; Kingman, S.W.; Gregory, D.H. Modern microwave methods in solid-state inorganic materials chemistry: From fundamentals to manufacturing. Chem. Rev. 2014, 114, 1170-1206. [CrossRef] [PubMed]

9. Zhu, Y.J.; Chen, F. Microwave-assisted preparation of inorganic nanostructures in liquid phase. Chem. Rev. 2014, 114, 6462-6555. [CrossRef] [PubMed]

10. Peng, Z.W.; Hwang, J.Y. Microwave-assisted metallurgy. Int. Mater. Rev. 2015, 60, 30-63. [CrossRef]

11. Schwenke, A.M.; Hoeppener, S.; Schubert, U.S. Synthesis and modification of carbon nanomaterials utilizing microwave heating. Adv. Mater. 2015, 27, 4113-4141. [CrossRef] [PubMed]

12. Singh, S.; Gupta, D.; Jain, V.; Sharma, A.K. Microwave processing of materials and applications in manufacturing industries: A review. Mater. Manuf. Process. 2015, 30, 1-29. [CrossRef]

13. Khan, N.A.; Jhung, S.H. Synthesis of metal-organic frameworks (MOFs) with microwave or ultrasound: Rapid reaction, phase-selectivity, and size reduction. Coord. Chem. Rev. 2015, 285, 11-23. [CrossRef]

14. Rattanadecho, P.; Makul, N. Microwave-assisted drying: A review of the State-of-the-Art. Dry. Technol. 2016, 34, 1-38. [CrossRef]

15. Wang, N.; Wang, P. Study and application status of microwave in organic wastewater treatment: A review. Chem. Eng. J. 2016, 283, 193-214. [CrossRef] 
16. Mishra, R.R.; Sharma, A.K. Microwave-material interaction phenomena: Heating mechanisms, challenges and opportunities in material processing. Composites: Part A 2016, 81, 78-97. [CrossRef]

17. Kelly, R.M.; Rowson, N.A. Microwave reduction of oxidised ilimenite concentrate. Miner. Eng. 1995, 8, 1427-1438. [CrossRef]

18. Kingman, S.W.; Corfield, G.M.; Rowson, N.A. Effects of microwave radiation upon the mineralogy and magnetic processing of a massive Norwegian ilmenite ore. Magn. Electr. Sep. 1999, 9, 131-148. [CrossRef]

19. Cutmore, N.; Evans, T.; Crnokark, D.; Middleton, A.; Stoddard, S. Microwave technique for analysis of mineral sands. Miner. Eng. 2000, 13, 729-736. [CrossRef]

20. Tong, Z.F.; Bi, S.W.; Yang, Y.H. Present situation of study on microwave heating application in metallurgy. J. Mater. Metall. 2004, 3, 117-120.

21. Itoh, S.; Suga, T.; Takizawa, H.; Nagasaka, T. Application of $28 \mathrm{GHz}$ Microwave irradiation to oxidation of ilmenite ore for new rutile extraction process. ISIJ Int. 2007, 47, 1416-1421. [CrossRef]

22. Fang, X.F.; Waters, K.E.; Rowson, N.A.; Parker, D.J. Modification of ilmenite surface chemistry for enhancing surfactants adsorption and bubble attachment. J. Colloid Interface Sci. 2009, 329, 167-172.

23. Guo, S.H.; Chen, G.; Peng, J.H.; Chen, J.; Li, D.B.; Liu, L.J. Microwave assisted grinding of ilmenite ore. Trans. Nonferrous Met. Soc. China 2011, 21, 2122-2126. [CrossRef]

24. Chen, G.; Chen, J.; Li, J.; Guo, S.H.; Srinivasakannan, C.; Peng, J.H. Optimization of combined microwave pretreatment-magnetic separation parameters of ilmenite using response surface methodology. Powder Technol. 2012, 232, 58-63. [CrossRef]

25. Zhao, W.; Chen, J.; Chang, X.D.; Guo, S.H.; Srinivasakannan, C.; Chen, G.; Peng, J.H. Effect of microwave irradiation on selective heating behavior and magnetic separation characteristics of Panzhihua ilmenite. Appl. Surf. Sci. 2014, 300, 171-177. [CrossRef]

26. Nuri, O.S.; Mehdilo, A.; Irannajad, M. Influence of microwave irradiation on ilmenite surface properties. Appl. Surf. Sci. 2014, 311, 27-32. [CrossRef]

27. Mehdilo, A.; Irannajad, M. Comparison of microwave irradiation and oxidation roasting as pretreatment methods for modification of ilmenite physicochemical properties. J. Ind. Eng. Chem. 2016, 33, 59-72. [CrossRef]

28. Guo, S.H.; Li, W.; Peng, J.H.; Niu, H.; Huang, M.Y.; Zhang, L.B.; Zhang, S.M.; Huang, M. Microwave-absorbing characteristics of mixtures of different carbonaceous reducing agents and oxidized ilmenite. Int. J. Miner. Process. 2009, 93, 289-293. [CrossRef]

29. Li, W.; Peng, J.H.; Guo, S.H.; Zhang, L.B.; Chen, G.; Xia, H.Y. Carbothermic reduction kinetics of ilmenite concentrates catalyzed by sodium silicate and microwave-absorbing characteristics of reductive products. Chem. Ind. Chem. Eng. Q. 2013, 19, 423-433. [CrossRef]

30. Li, W.; Peng, J.H.; Guo, S.H.; Zhang, L.B.; Chen, G.; Xia, H.Y.; Liu, B.G. Carbothermic reduction kinetics of ilmenite concentrates catalyzed by sodium chloride and microwave-absorbing characteristics of reductive products. Miner. Metall. Process. 2013, 30, 108-116.

31. Li, W.; Peng, J.H.; Guo, S.H.; Zhang, L.B.; Chen, G.; Xia, H.Y.; Liu, B.G. Carbothermic reduction kinetics of ilmenite concentrates catalyzed by sodium chloride and sodium borate and microwave-absorbing characteristics of reductive products. Metal. Int. 2013, 18, 19-25.

32. Wang, X.Y.; Li, W.; Yang, B.; Guo, S.H.; Zhang, L.B.; Chen, G.; Peng, J.H.; Luo, H.L. Microwave-absorbing of carbothermic reduced products of ilmenite and oxidized ilmenite. J. Microw. Power Electromag. Energ. 2014, 48, 192-202. [CrossRef]

33. Liu, C.H.; Zhang, L.B.; Peng, J.H.; Liu, B.G.; Xia, H.Y.; Gu, X.C.; Shi, Y.F. The effect of temperature on dielectric property and microwave heating behavior of low grade Panzhihua ilmenite ore. Trans. Nonferrous Met. Soc. China 2013, 23, 3462-3469. [CrossRef]

34. Huang, M.; Peng, J.H.; Yang, J.J.; Wang, J.Q. Microwave cavity perturbation technique for measuring the moisture content of sulphide minerals concentrates. Miner. Eng. 2007, 20, 92-94. [CrossRef]

35. Huang, M. Non-Destructive Detection Method for Egg Freshness by Using Electromagnetic Wave Resonant Cavity. China Patent 02125071.5, 21 June 2006.

36. Carter, R.D. Accuracy of microwave cavity perturbation measurements. Microwave theory and techniques. IEEE Trans. Microw. Theory Tech. 2001, 49, 918-923. [CrossRef]

(C) 2016 by the authors; licensee MDPI, Basel, Switzerland. This article is an open access article distributed under the terms and conditions of the Creative Commons Attribution (CC-BY) license (http://creativecommons.org/licenses/by/4.0/). 